\title{
Dynamic Optimizations of Cultivation and Fruit-Storage Processes Using a Speaking Plant-based Intelligent Control Technique
}

\author{
Tetsuo Morimoto \\ Department of Biomechanical Systems, Ehime University, Tarumi, Matsuyama 790-8566, Japan
}

(Received June 6, 2003)

\begin{abstract}
This paper presents applications of a 'speaking plant'-based intelligent control technique to dynamically optimize hydroponic cultivation and fruit-storage processes. Tomato growth during the seedling stage was optimized by nutrient concentration of a hydroponic solution in a cultivation process. Similarly, for the storage process, the rate of water loss in tomatoes was minimized by temperature control. The control system comprises a decision system and a feedback control system. The former is used for determining the optimal set point profile ( $l$-step set points) of the environment based on plant responses, whereas the latter controls the environment based on the optimal set point profile. The optimal set point profile of the nutrient concentration of the solution during the seedling stage was a slightly high level $(1.4 \mathrm{mS} / \mathrm{cm})$ during the first few days, a markedly low level $(0.3 \mathrm{mS} / \mathrm{cm})$ during the second few days, a slightly high level $(1.6 \mathrm{mS} / \mathrm{cm})$ during the third few days, and the maximum level $(2.0 \mathrm{mS} / \mathrm{cm})$ during the last stage (flowering stage of the first truss) under the range of 0.3 to $2.0 \mathrm{mS} / \mathrm{cm}$. This operation promoted reproductive growth of the tomato. In the storage process, on the other hand, the optimal temperature operation that first rises to a high level $\left(40^{\circ} \mathrm{C}\right)$ for a day and then suddenly drops to the minimum level $\left(15^{\circ} \mathrm{C}\right)$ under the range of 15 to $40^{\circ} \mathrm{C}$ provided lower values of the rate of water loss than when the temperature was maintained constantly at the lowest level throughout the entire control process. These results suggest that dynamic optimization using a speaking plant-based intelligent control technique is useful for qualitative improvement of both the plant during cultivation and the fruit during storage.
\end{abstract}

Keywords: plant control system, cultivation and storage processes, speaking plant approach, dynamic optimization, intelligent control

\section{INTRODUCTION}

In recent years, many sensors and computers have been rapidly introduced into plant production systems such as greenhouses and plant factories, which have brought about many changes in routine for production tasks. At the same time, advanced control techniques for the greenhouse environment have been developed to achieve optimization of environmental greenhouse variables such as temperature, relative humidity, and $\mathrm{CO}_{2}$ concentration (Marsh and Albright, 1991 ; Chalabi et al., 1996; Sigrimis and Rerras, 1996 ; Ioslovich and Seginer, 1998). However, optimization of plant growth has been not realized yet because studied

Corresponding author: Tetsuo Morimoto, fax : +1-89-946-9916, e-mail : morimoto@agr.ehime-u.ac.jp 
control variables have only been restricted to environmental factors and have not included any physiological plant responses.

Monitoring physiological status of the plant and then using this information for control is effective to realize optimization of plant production processes. In practice, measurement and identification (modeling) of plant responses and the use of that plant model in making a decision on optimal strategy for management may be necessary. Such an approach is known as the 'speaking plant approach (SPA)' (Hashimoto, 1980 and 1989; Challa and van Straten, 1993 ; Tantau, 1993). Both identification of plant responses and optimal control of a greenhouse environment based on the concept of SPA have been achieved (Hashimoto et al., 1984a and 1984b; Challa and Straten, 1993; Tantau, 1993).

In general, however, it is difficult to achieve optimization dynamically because interactions between plant responses and environmental factors are difficult to understand as a result of the complexity of physical and physiological processes involved.

Intelligent control techniques are more suitable than traditional mathematical methods for dealing with complex systems such as cultivation systems (Hashimoto, 1997). The present work has focused on intelligent control techniques including neural networks and genetic algorithms. Neural networks offer the capability to identify unknown complex systems with their own learning ability (Chen et al., 1990). Genetic algorithms are one combinatorial optimization technique. They seek an optimal value (or a near-global one) of a complex objective function by a multi-point search procedure; they simulate a biological evolutionary process based on crossover and mutation in genetics (Goldberg, 1989; Holland, 1992).

This article provides the application of a 'speaking plant'-based intelligent control technique consisting of a decision system and a feedback control system to optimization of two kinds of plant production processes, hydroponic cultivation and storage processes of tomatoes. In hydroponic optimization, the control input is nutrient concentration of the solution and the controlled output is tomato growth. For storage optimization, the control input is temperature, and the controlled output is the rate of water loss of tomatoes.

\section{SPEAKING PLANT APPROACH (SPA) AND SPEAKING FRUIT APPROACH (SFA)}

Environmental factors during cultivation are usually maintained constant at the adequate level, already determined as an optimal value, without any consideration of the physiological status of the fruit. In order to achieve the qualitative improvement of the plant, however, it is essential to control the environment flexibly and optimally, taking the physiological status of the plant into consideration. Measurement of the plant responses and the control based on their physiological information are major tasks for realizing the optimization of the cultivation process. The environmental factors in the cultivation process should be controlled optimally based on plant responses. This approach is explored as a 'speaking plant approach (SPA)', where the environmental factors are considered to be the input and the plant responses the output (Hashimoto, 1980 and 1989; Challa and van Straten, 1993; Tantau, 1993; Morimoto et al., 1995 and 1996). The term 'speaking plant (SP)' refers to plant responses measured by sensors.

As the next step, it should be expected that this approach might also be effective in the fruit storage process as well as in the greenhouse. This should be a so-called 'speaking fruit approach (SFA)' (De Baerdemaeker and Hashimoto, 1994 ; Morimoto et al., 1997a, 1997b and 2000). It is clear that the storage process for fruit is more controllable than the cultivating process.

Figure 1 shows the schematic diagram of the speaking plant-based control system for a total plant production process, consisting of a cultivation process for plants grown in 


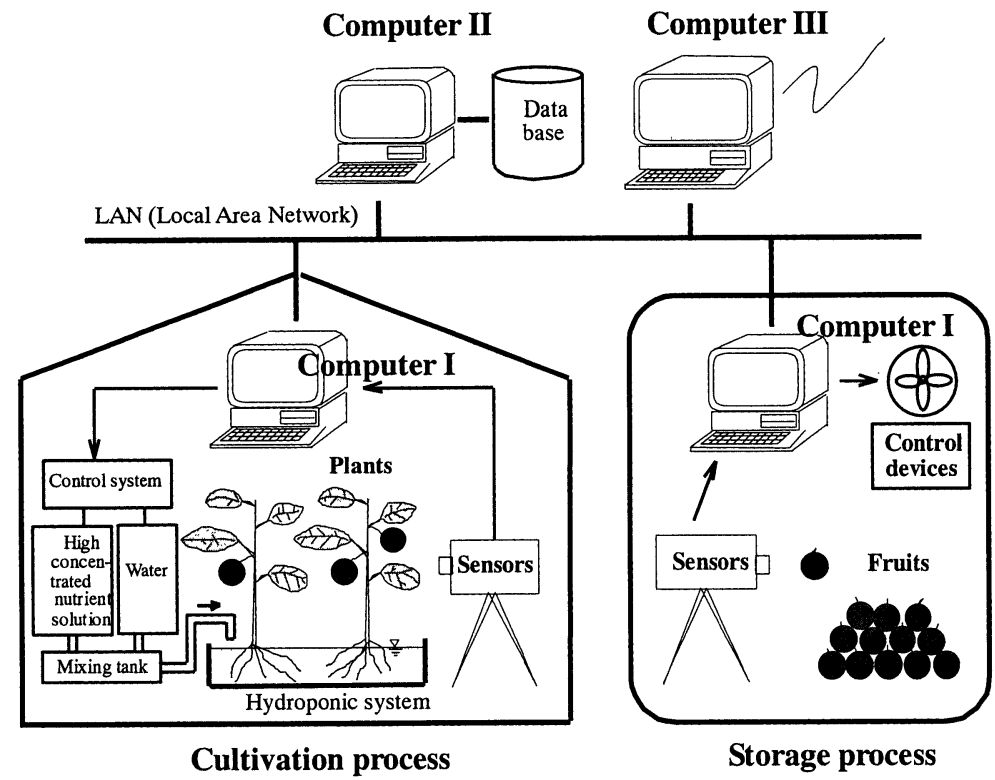

Fig. 1 Schematic diagram of the 'speaking plant'-based control system for a total production process consisting of a hydroponic cultivation process and a fruit-storage process.

hydroponics and a storage process for fruit. In general, plant control systems can be complex, large-scale systems involving many management tasks. Here, a decentralized computer control system with a hierarchical structure aimed at effectively using existing computers is proposed. It consists of several sensors to measure the physiological responses of the plant (or fruit) responses, three types of computers : a computer I for determining the optimal set point of the environment and controlling the environment based on the optimal set points, a computer II for diagnosing plant growth and disease using data base and a computer III for communicating with other computers through internet, and control devices for controlling the greenhouse (or storage) environment. Non-destructive measurements of plant responses (or fruit responses) are essential for realizing the dynamic control for optimization.

\section{DYNAMIC OPTIMIZATION PROBLEMS}

\section{Optimization problem $I$ in the hydroponic cultivation process}

Hydroponic culture techniques are suitable for both flexible control of the root-zone environment of plants and for mechanization of cultivation processes (Gale and Ben-Asher, 1983). The technique behind good fruit yields in tomato cultivation is to maintain an optimal balance between vegetative growth (e.g., root, stem and leaf growth) and reproductive growth (e.g., flower and fruit growth). In hydroponic cultivation, however, vegetative growth becomes more active than reproductive growth because plant roots always exist in a suitable environment for the uptake of nutrient ions. Active vegetative growth induces poor reproductive growth.

In the cultivation of tomatoes, the balance between the two types of growth is determined at the seedling stage. Therefore, this study applies optimization control at that stage. Only stem growth, leaf growth and root growth are visible during the seedling stage. Luo and Kato (1987) demonstrated that the $S / R$ ratio ( $\mathrm{S}$ : stem dry weight, $\mathrm{R}$ : root dry weight) is a good indicator for predicting future growth, and that smaller values result in better yields. The 
experiment in this paper also indicated that larger stem growth resulted in poor flowering (Fukuyama et al., 1986). However, in this case, leaf growth was used as one of the predictors because measuring leaf growth is much easier than measuring root growth. It was also assumed that larger leaf growth is advantageous for promotion of photosynthate production of the plant because the area performing photosynthesis is increased (Fukuyama et al., 1986). From these findings, the ratio, TLL/SD, of total leaf length (TLL) to stem diameter (SD) was defined as a predictor for the future plant growth. As a matter of fact, higher values of TLL/ $\mathrm{SD}$ resulted in better reproductive growth. Therefore, controls for maximizing TLL/SD may be of value only during the seedling stage.

The nutrient concentration of the solution in hydroponics is one of the most important control factors for adjusting the balance between the two types of growth (Ehret and Ho, 1986). Most skilled growers usually increase the nutrient concentration as plants grow.

The optimization problem for the cultivation process is to determine an optimal set point profile of nutrient concentration to optimize the balance between the two types of growth only during the seedling stage.

Let $\operatorname{TLL}(\mathrm{k}) / \mathrm{SD}(\mathrm{k})$ be a time series of TLL/SD, as affected by nutrient concentration $\mathrm{NC}(\mathrm{k})$ $(\mathrm{k}=1, \ldots, \mathrm{N}$ : sampling day, $\mathrm{N}$ : final day). The control input is $\mathrm{NC}(\mathrm{k})$ and the controlled output is $\operatorname{TLL}(\mathrm{k}) / \mathrm{SD}(\mathrm{k})$.

The seedling stage $(1 \leq \mathrm{k} \leq \mathrm{N})$ was divided into four stages for implementation : 1) transplanting, 2) vegetative growth after transplanting, 3) flowering of the first truss, and 4) fruit setting for the first truss and flowering for the second truss. Values of TLL $(k) / \operatorname{SD}(k)$ at the last stage (stage 4) were evaluated. The value of the nutrient concentration (=control input) in each stage, $\mathrm{NC}_{1}, \mathrm{NC}_{2}, \mathrm{NC}_{3}$ or $\mathrm{NC}_{4}$, was kept constant $\left\{\mathrm{NC}_{1}=\mathrm{NC}(1), \ldots, \mathrm{NC}\left(\mathrm{N}_{1 \mathrm{~L}}\right), \mathrm{NC}_{2}=\right.$ $\mathrm{NC}\left(\mathrm{N}_{1 \mathrm{~L}}+1\right), \ldots, \mathrm{NC}\left(\mathrm{N}_{2 \mathrm{~L}}\right), \mathrm{NC}_{3}=\mathrm{NC}\left(\mathrm{N}_{2 \mathrm{~L}}+1\right), \ldots, \mathrm{NC}\left(\mathrm{N}_{3 \mathrm{~L}}\right)$, and $\mathrm{NC}_{4}=\mathrm{NC}\left(\mathrm{N}_{3 \mathrm{~L}}+1\right), \ldots$, $\mathrm{NC}(\mathrm{N}) ; \mathrm{N}_{1 \mathrm{~L}}, \mathrm{~N}_{2 \mathrm{~L}}, \mathrm{~N}_{3 \mathrm{~L}}$ and $\mathrm{N}$ : the last days of the first, second, third and fourth stages $\}$.

An objective function, $F_{1}(\mathrm{NC})$, was given by the average value of TLL/SD at the last stage (stage $\left.4, N_{3 L}+1 \leq k \leq N\right)$ in its dynamic response as follows $\left(N_{3 L}+1\right.$ : first day of the stage 4) :

$$
\mathrm{F}_{1}(\mathrm{NC})=\sum_{\mathrm{k}=\mathrm{N} 3 \mathrm{~L}+1}^{\mathrm{N}} \mathrm{TLL}(\mathrm{k}) / \mathrm{SD}(\mathrm{k}) /\left(\mathrm{N}-\mathrm{N}_{3 \mathrm{~L}}+1\right)
$$

Thus, the optimization problem is to determine the optimal four-step set points of nutrient concentration, $\mathrm{NC}_{1}, \mathrm{NC}_{2}, \mathrm{NC}_{3}$ and $\mathrm{NC}_{4}$, which maximize $\mathrm{F}_{1}(\mathrm{NC})$ using a decision system. Nutrient concentration during the seedling stage was constrained to $0.2 \leq \mathrm{NC}(\mathrm{k}) \leq 2.0(\mathrm{mS} /$ $\mathrm{cm})$ through preliminary experiments.

maximize $\mathrm{F}_{1}(\mathrm{NC})$

subject to $0.2 \leq \mathrm{NC}(\mathrm{k}) \leq 2.0(\mathrm{mS} / \mathrm{cm})$

\section{Optimization problem II in the storage process}

Freshness is one of the most important evaluation criteria by which consumers select tomatoes at a green market. Storage temperature is usually maintained constant at a lower level to maintain tomato freshness during storage. This is because the low temperature effectively reduces microbial spoilage and water loss of the fruit. In recent years, however, it has been reported that a heat stress application is also effective to maintain fruit quality (Liu, 1978 ; Biggs et al., 1988 ; Shellie and Mangan, 1994 ; Hofman et al., 2000). This is probably because of thermo-tolerance of the fruit acquired by heat stress.

It is well known that the exposure of living organisms to heat stress produces several types of heat shock proteins (HSPs) in their cells, which acquire transient thermo-tolerance (Chen et al., 1982 ; Kimpel and Key, 1985). Recently, the relationships between the heat treatment and HSPs have been investigated to elucidate the effects of heat treatment (Sabehat et al., 1996). 
Acquiring thermo-tolerance may lead to the reduction of the water loss for fruits during storage (Paull and Chen, 2000). It is, therefore, important to know how we apply the heat stress to the fruit in order to minimize loss of quality. An optimal control technique will give us the solution.

Let $\mathrm{W}_{\mathrm{T}}(\mathrm{k})(\mathrm{k}=1,2, \ldots, \mathrm{N})$ be a time series of the rate of the water loss, as affected by temperature $T(k)$, at the time $k$. An objective function, $F_{2}(T)$, was given by the average value of the rate of the water loss during the last period $\left(\mathrm{N}_{\mathrm{L}} \leq \mathrm{k} \leq \mathrm{N}\right)$ of the control process. $\mathrm{N}_{\mathrm{L}}$ and $\mathrm{N}$ are the first and last time points in the evaluation period.

$$
\mathrm{F}_{2}(\mathrm{~T})=\sum_{\mathrm{k}=\mathrm{N}_{\mathrm{L}}}^{\mathrm{N}} \mathrm{W}_{\mathrm{T}}(\mathrm{k}) /\left(\mathrm{N}-\mathrm{N}_{\mathrm{L}}+1\right)
$$

The control process was divided into $l$ steps for realizing optimization. Therefore, the optimization problem here is to determine the $l$-step set points of the temperature that minimize the objective function $F_{2}(T)$. That is, an optimal value is given by the optimal combination of the $l$-step set points for temperature. For the temperature constraint, we had two minimum temperatures $\left(\mathrm{T}_{\min }=5\right.$ and $\left.15^{\circ} \mathrm{C}\right)$ to investigate the influence of heat stress at adequate temperature levels. As for maximum temperature, $40^{\circ} \mathrm{C}$ was determined to be best for heat stress from considerations of the one-day application of heat stress and tomato species and, therefore, it was fixed at $40^{\circ} \mathrm{C}$.

minimize $\mathrm{F}_{2}(\mathrm{~T})$

subject to $\mathrm{T}_{\min } \leq \mathrm{T}(\mathrm{k}) \leq 40^{\circ} \mathrm{C}$

\section{Experimental conditions}

Tomato plants (Lycopersicon esculentum Mill. cv. Momotaro) grown in a deep hydroponic system were used for the optimization of the cultivation process. All growth experiments were carried out in a greenhouse where only the temperature was controlled at an adequate level. The light intensity was arbitrary. The total leaf length (TLL) and stem diameter (SD) in the tomato were measured every day using an image processing system (Mitsubishi, MELFA IS-100H) and a ruler.

For storage process optimization, on the other hand, mature green tomatoes (cv. Momotaro) of uniform size (about $8 \mathrm{~cm}$ in diameter) were stored in a storage chamber (Tabai-espec, LHU-112M), in which temperature and relative humidity are strictly controlled by a personal computer with an accuracy of $\pm 0.1^{\circ} \mathrm{C}$ and $\pm 2 \% \mathrm{RH}$, respectively. The rate of the water loss of the tomato was estimated from the weight loss. The weight loss of the tomato was continuously measured by hanging a cage containing three tomatoes using an electronic balance (Sartorius, LP-620S). In this case, the electronic balance was set outside of the chamber in order to remove the effect of the temperature change. The relative humidity was maintained constant at $60 \pm 2 \% \mathrm{RH}$ while only the temperature was flexibly changed based on a system control manner. The sampling time was 10 minutes.

\section{DESIGN OF A SPEAKING PLANT-BASED CONTROL SYSTEM}

\section{A speaking plant (or fruit)-based intelligent control system}

How is the optimization of plant (or fruit) responses realized based on the SPA (or SFA) concept? Figure 2 shows the block diagram of a 'speaking plant'-based intelligent control system for realizing the dynamic optimization of plant responses (Morimoto et al., 1995 and 1996). It consists of a decision system and a feedback control system. The decision system consisting of neural networks and genetic algorithms determines the optimal set point profile ( $l$-step set points) of the environment based on plant responses. In the decision system, the plant responses (or fruit responses), as affected by the environment, is first identified using the 


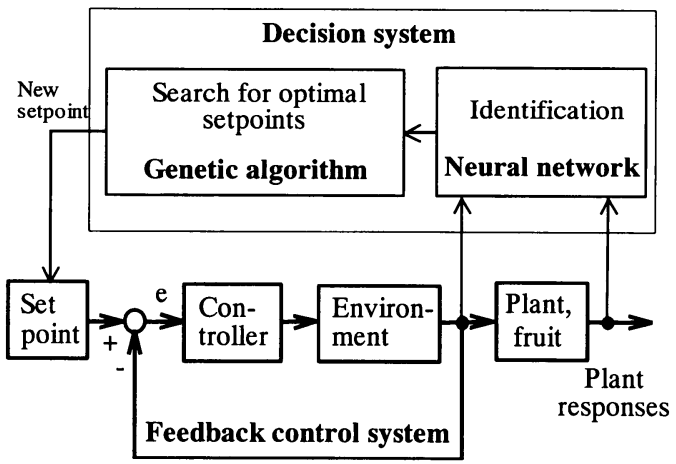

Fig. 2 Block diagram of a 'speaking plant'-based control system consisting of a decision system, for determining the optimal environmental set points, and a feedback control system for controlling the environment based on the optimal set points.

neural network, and then the optimal combination of the $l$-step set points of the environment that minimize (or maximize) the objective function is searched for through simulation of the identified neural-network model using the genetic algorithm. Furthermore, the optimal $l$-step set points are sequentially applied to the set point in the feedback control system.

It will be found that if these two procedures, identification and the search for an optimal value, are repeated periodically every stages in a storage process to adapt the time-variation of the physiological status of the fruit, both optimization and adaptation can be satisfied.

\section{Artificial neural networks}

\subsection{Structure of artificial neural networks}

Artificial neural networks in the decision system were used for creating black-box models for simulation, which predict plant responses to environmental factors. For identification purposes, arbitrary feedback loops that produce time histories of the data are necessary elements of the network (Isermann et al., 1997). The well-known time-delay neural-network model is given as (Narendra and Parthasarathy, 1990) :

$$
\mathrm{y}(\mathrm{k})=\mathrm{f}(\mathrm{u}(\mathrm{k}), \mathrm{u}(\mathrm{k}-1), \ldots, \mathrm{u}(\mathrm{k}-n), \mathrm{y}(\mathrm{k}-1), \ldots, \mathrm{y}(\mathrm{k}-n))
$$

where $n$ is the system order (number of system parameters). The unknown function $f(\cdot)$ can be approximated by a static neural network.

Figure 3 (a) and (b) show time-delay neural networks used for identifying the dynamics of plant responses to environmental factors. They consist of three layers. Figure 3 (a) identifies the response of the $\operatorname{TLL}(\mathrm{k}) / \mathrm{SD}(\mathrm{k})$ ratio to two inputs (nutrient concentration, $\mathrm{NC}(\mathrm{k})$, and light intensity, L(k)) (Morimoto et al., 1991 ; Isermann et al., 1997). The current output TLL $(\mathrm{k}) / \mathrm{SD}(\mathrm{k})$ is estimated from both the historical input data $\{\mathrm{NC}(\mathrm{k}), \ldots, \mathrm{NC}(\mathrm{k}-$ $\left.\left.n_{1}\right), \mathrm{L}(\mathrm{k}), \ldots, \mathrm{L}\left(\mathrm{k}-n_{1}\right)\right\}$ and from the historical output data $\left\{\mathrm{y}(\mathrm{k}-1), \ldots, \mathrm{y}\left(\mathrm{k}-n_{1}\right)\right\}$. Figure 3 (b) identifies the responses of the rate of the water loss of tomatoes to the temperature. The current output $\mathrm{W}_{\mathrm{T}}(\mathrm{k})$ is estimated from both the historical input data $\left\{\mathrm{T}(\mathrm{k}), \ldots, \mathrm{T}\left(\mathrm{k}-n_{2}\right)\right\}$ and the historical output data $\left\{\mathrm{W}_{\mathrm{T}}(\mathrm{k}-1), \ldots, \mathrm{W}_{\mathrm{T}}\left(\mathrm{k}-n_{2}\right)\right\}$. Their learning methods were error back-propagation (Rumelhart et al., 1986).

\subsection{Model validation}

In each case, the data samples are divided into two data sets, a training data set and a testing data set. The former is used for training the neural network, and the latter for evaluating the accuracy of the identified model. The testing data sets have to be independent 

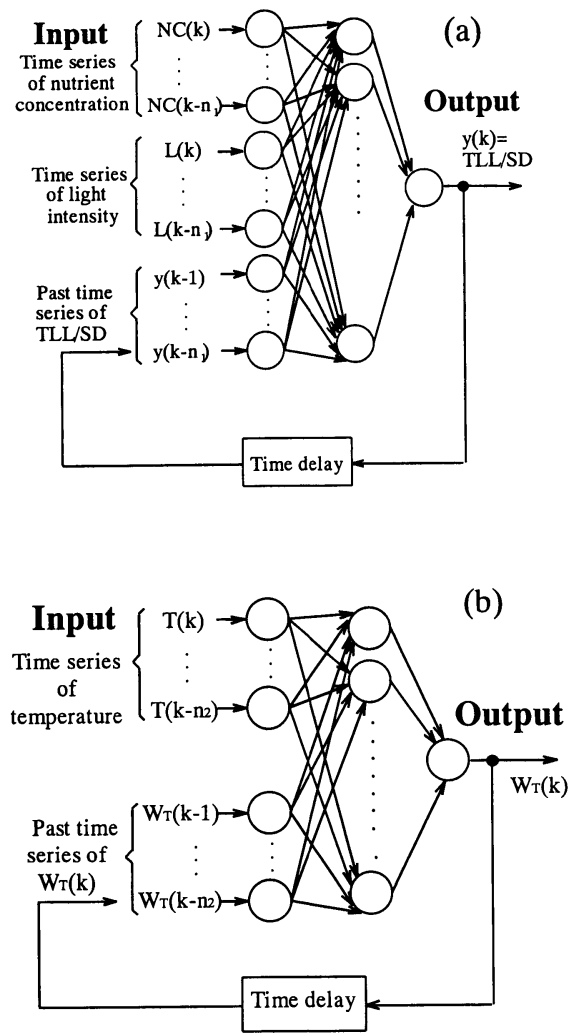

Fig. 3 Schematic diagrams of time-delay neural networks used for identifying the plant responses to environmental factors. (a) : the $\operatorname{TLL}(\mathrm{k}) / \mathrm{SD}(\mathrm{k})$ to nutrient concentration $\mathrm{NC}(\mathrm{k})$ and light intensity $\mathrm{L}(\mathrm{k}),(\mathrm{b})$ : the rate of the water loss $\mathrm{W}_{\mathrm{T}}(\mathrm{k})$ to temperature $\mathrm{T}(\mathrm{k})$.

from the training data sets. This type of model validation is called 'cross-validation'.

\subsection{Choice of model structure}

The most important task for determining the model's structure is the choice of the system order. In each case, the system order and the hidden-neuron number of the neural-network were determined based on the cross-validation.

\section{Genetic algorithms}

\subsection{Definitions of individuals and their cording patterns}

In order to employ genetic algorithms, an 'individual' for genetic evolution has to be defined as the first step. Each individual represents a candidate for an optimal solution (one possible solution).

In optimization problem I, since the aim is to determine the four-step set points of the nutrient concentrations which maximizes $F_{1}(\mathrm{NC})$, the four-step set points of the nutrient concentration, $\mathrm{NC}_{1}, \mathrm{NC}_{2}, \mathrm{NC}_{3}$ and $\mathrm{NC}_{4}$, represents an individual and each nutrient concentration is coded as a six-bit binary string. The genetic algorithms work under a finite-length of binary strings. The simple bound constraints were $0.2 \leq \mathrm{NC}_{l} \leq 2.0(\mathrm{mS} / \mathrm{cm})$.

$$
\text { Individual }=\mathrm{NC}_{1}, \mathrm{NC}_{2}, \mathrm{NC}_{3}, \mathrm{NC}_{4}=100100,001001,001100,101010
$$

In optimization problem II, on the other hand, since the purpose is to determine the $l$-step 
set points of the temperature which minimizes $\mathrm{F}_{2}(\mathrm{~T})$, the $l$-step set points of the temperature, $\mathrm{T}_{1}, \mathrm{~T}_{2}, \ldots, \mathrm{T}_{l}$, represents an individual and each temperature is coded as a six-bit binary string as follows. The simple bound constraints were $\mathrm{T}_{\min } \leq \mathrm{T}_{l} \leq 40^{\circ} \mathrm{C}$.

$$
\text { Individual }=\mathrm{T}_{1}, \mathrm{~T}_{2}, \ldots, \mathrm{T}_{l}=100100,001001, \ldots, 001100
$$

A set of individuals is called a 'population'. They evolve toward better solutions. Genetic algorithms work with a population involving many individuals. The population size varies according to the use of genetic operations. Noted that smaller population size tends to converge to a local optima.

\subsection{Definition of fitness}

Fitness is an indicator for measuring an individual's survival quality. All individuals are evaluated in terms of their performances, which are based on their fitness values. During the evolution process, therefore, individuals having higher fitness reproduce, and individuals with lower fitness die in each generation. An individual having the maximum fitness is regarded as an optimal solution. Fitness is similar to the objective function in conventional optimization problems. So, fitness in problem I can be represented by Eq. (1), and fitness in problem II by Eq. (2).

\subsection{Genetic operations}

Crossover combines features from two parent structures to form two similar offspring. It operates by swapping corresponding components in the binary strings representing the parent. Here, two-point crossovers were used. The mutation inverts one or more components of the binary strings (=individual), selected at random from the population, from 0 to 1 or vice versa. The mutation operation increases the variability of the population and helps to avoid the possibility of falling into a local optima in the evolution process (Krishnakumar and Goldberg, 1992).

\subsection{Procedure of genetic algorithm}

Figure 4 shows the procedure of the genetic algorithm used here. 1) An initial population consisting of several individuals is generated at random. 2) New individuals in another population are added to the original population to maintain diversity. 3) Crossover and mutation operations are applied to the individuals selected at random. 4) The fitness values of all individuals are calculated using the neural-network model and their performances are

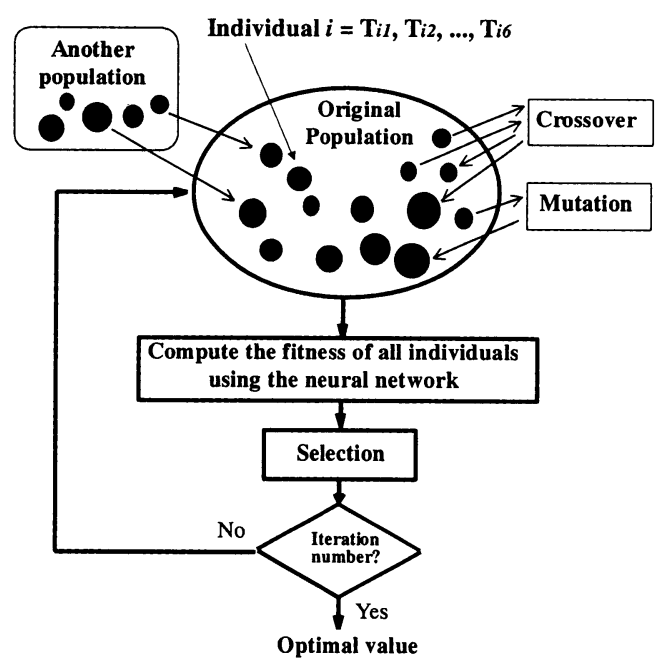

Fig. 4 Flow chart of the genetic algorithm used for searching for an optimal value. 
evaluated. 5) Superior individuals are selected and retained for the next generation (Selection). 6) Steps 2 to 5 are repeated until an arbitrary condition is satisfied. An optimal value is given as an individual with highest fitness. An elitist strategy was used for selection.

\section{DYNAMIC OPTIMIZATION IN THE HYDROPONIC PROCESS}

\section{Dynamic response of the $T L L / S D$ ratio to nutrient concentration}

First, the data for identification were obtained. Figure 5 shows the observed daily changes in the TLL/SD ratio observed for tomato plants grown in hydroponics, as well as the light intensity and nutrient concentration of the solution during the seedling stage. The control process is restricted to the seedling stage. Three patterns of the TLL/SD ratio under three different nutrient concentration treatments are shown. Morimoto et al. (1997c) found that three or more data sets are necessary for identification. This data was measured every day using an image-processing unit and a ruler. The light condition is arbitrary. It was found that the value of the TLL/SD ratio is markedly affected by nutrient concentration. For identification, the data for $\mathrm{N}=22$ was obtained in each pattern.

The response of the TLL/SD ratio to both nutrient concentration and light intensity is then identified by a neural network, and a black-box model for predicting the TLL/SD ratio is created.

\section{Identification results}

Figure 6 shows the identification result in the response of the TLL/SD ratio to both light intensity and nutrient concentration by the neural network shown in Fig. 3(a). The data used here was independent of the data in Fig. 5. $n_{1}=1$ was selected as the system order to save computing time. It was also found that the number of hidden neurons $\mathrm{n}_{\mathrm{h} 1}=5$ was best for cross-validation. It was found that the estimated responses were closely related to the
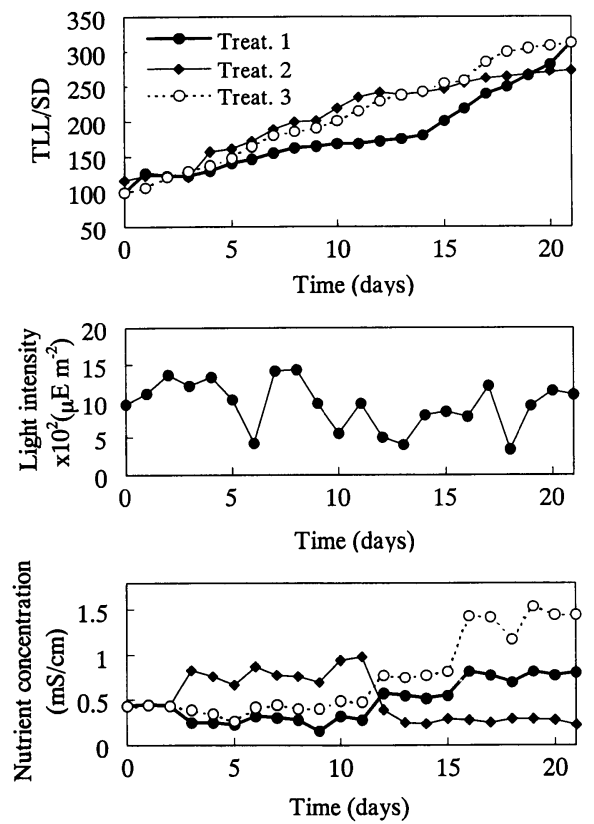

Fig. 5 The observed daily changes in the TLL/SD ratio of tomato plants grown in hydroponics, and the light intensity and nutrient concentration of the solution during the seedling stage. 


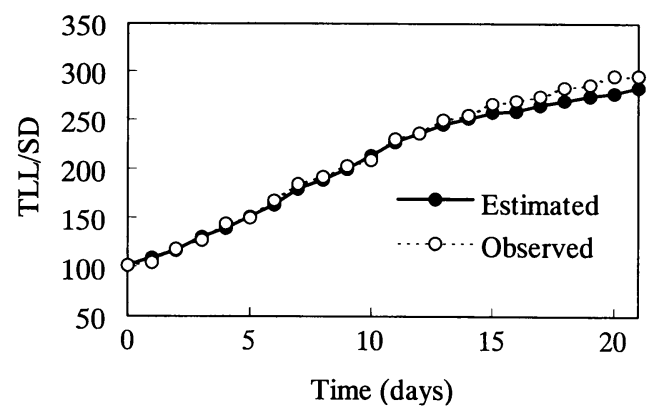

Fig. 6 A comparison of the estimated response and the observed response of the TLL/SD ratio.

observed responses. This result means that a reliable computational model could be obtained for predicting the behavior of the TLL/SD ratio under any combination of the four-step set points of nutrient concentration.

\section{Search characteristics for optimal set points of nutrient concentration}

Figure 7 shows the evolution curves during the search for an optimal value under different crossover and mutation rates. The fitness in all cases dramatically increased, and then reached a maximum value. However, the degree of increase can be seen to be larger for higher crossover and mutation rates than for lower crossover and mutation rates. For example, the fitness reached a maximum value at the ninth generation when the crossover and mutation rates were high $\left(P_{c}=0.8\right.$ and $\left.P_{m}=0.8\right)$. When the crossover and mutation rates were low $\left(P_{c}=0.2\right.$ and $P_{m}=0.02$ ), however, the fitness could not reach the maximum value and fell into a local optimum. This is probably due to the loss of diversity in the population caused by low crossover and mutation rates.

Noted that there is no guarantee that genetic algorithms yield a global optimal solution. It is, therefore, important to confirm whether an optimal value determined by genetic algorithm is global or local. In this paper, the confirmation was mainly carried out using a round-robin algorithm which systematically searches for all values (possible solutions) around the optimal solution at the proper step. This is because a near global optimal solution can at least be obtained by genetic algorithms. An optimal solution was also confirmed with a different initial population and different methods of crossover and mutation. Through these procedures, a global optimal solution was confirmed.

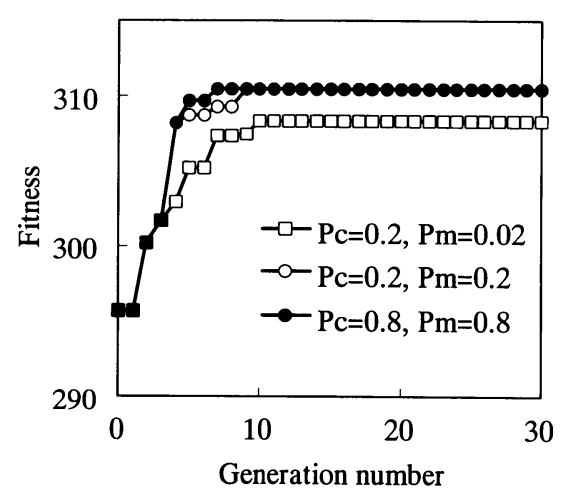

Fig. 7 Evolution curves of the search for an optimal value under different crossover and mutation rates. 


\section{Optimal control of the TLL/SD ratio during the seedling stage}

Figure 8 shows an estimated control result calculated from the model simulation by the neural network. The upper figure is the estimated optimal control performance of the TLL/ SD ratio. The lower figure represents the optimal four-step set points of nutrient concentration (control input) obtained by the decision system. In the present study, the nutrient concentration was limited to the range 0.3 to $2.0(\mathrm{mS} / \mathrm{cm})$. The control strategy recommended maintaining a slightly higher level $(1.4 \mathrm{mS} / \mathrm{cm})$ in the first stage, a markedly lower level (0.3) in the second stage, a slightly higher level (1.6) in the third stage and the maximum level (2.0) in the fourth stage. In hydroponics, as mentioned above, since the roots of plants always exist in a suitable environment for the uptake of any nutrient ions, the vegetative growth during the seedling stage is easy to promote. Active vegetative growth during the seedling stage will result in a poor reproductive growth in the future (Hurd, 1978 ; Ehret and Ho, 1986 ; Mizrahi et al., 1986). Therefore, vegetative growth must be suppressed at the early seedling stage, before the flowering of the first truss. The low nutrient concentration in the second stage seems to be effective in suppressing the excessive vegetative growth during the seedling stage. The high nutrient concentrations in the third and fourth stages appear to be useful in accelerating reproductive growth (i.e., the flowering of the first and second trusses, and the fruit-setting of the first truss during the seedling stage).

Figure 9 shows the actual control performance of the TLL/SD ratio. The solid line shows the optimal control performance and the dotted line represents conventional control performance. The conventional strategy is simply to increase the nutrient concentration in a stepwise fashion with the growth of the plants. In order to make the difference between the
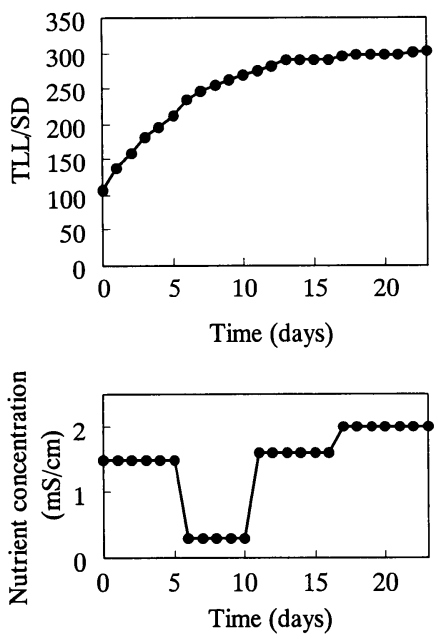

Fig. 8 The estimated optimal control performance of the TLL/SD ratio to nutrient concentration.
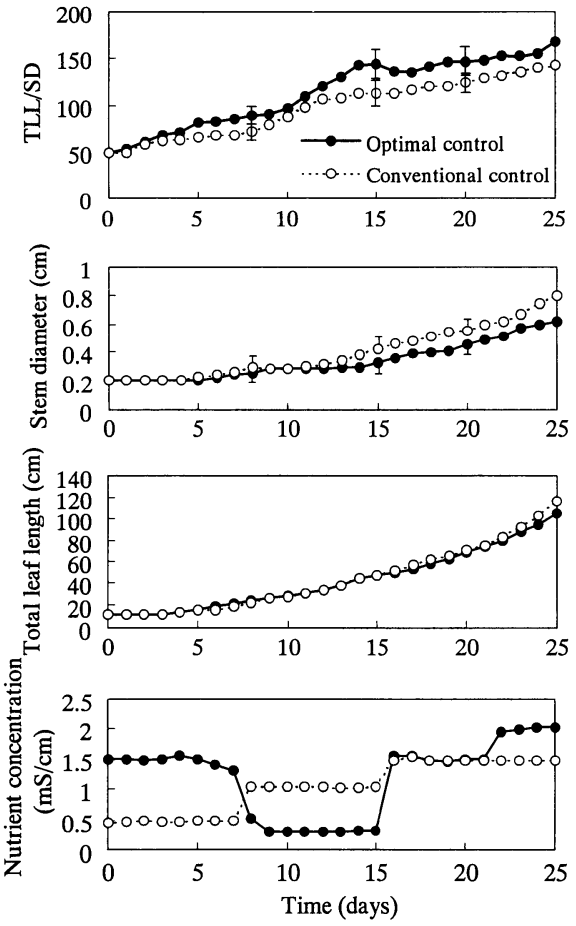

Fig. 9 Actual optimal control performance of the TLL/SD ratio to optimal four-step set points of nutrient concentration. 
two control performances clear, standard deviations were calculated and a t-test was then carried out. Comparing both control performances, it is apparent that the values of the TLL/ SD ratio are $10-15 \%$ higher with the optimal control than with the conventional control. This result was confirmed from a t-test at the $5 \%$ level of significance. This is because with the optimal control stem growth was significantly suppressed by the low nutrient concentration at the second step, while in both cases the leaf growth is not very different. Thus, the effectiveness of the decision system for the optimal control of plant growth was also confirmed experimentally.

\section{DYNAMIC OPTIMIZATION IN THE STORAGE PROCESS}

\section{Dynamic responses of the rate of the water loss to temperature}

Several basic responses of the rate of the water loss were obtained before identifying the fruit responses. Figure 10 shows a typical response of the rate of the water loss, as affected by the temperature. The temperature was first increased such as $25 \rightarrow 35 \rightarrow 40^{\circ} \mathrm{C}$ and then decreased such as $40 \rightarrow 35 \rightarrow 25^{\circ} \mathrm{C}$. It is found that the rate of the water loss varies with the temperature. Comparing to the two values of the rate of the water loss at the same temperature, before increasing and after dropping the temperature, it is found that the values after dropping the temperature are lower than those before increasing the temperature at both 25 and $35^{\circ} \mathrm{C}$ conditions. These results suggest that a temperature operation that first rises and then drops to the lowest level provides a lower water loss than when the temperature was maintained constantly at the lowest level throughout the entire control process.

Next, the data for identification were obtained. Figure 11 shows eight types of dynamic changes in the rate of the water loss (controlled output), as affected by temperature (control input), for about 192 hours. These are all training data sets for training the neural network. The temperature was flexibly changed between 5 and $40^{\circ} \mathrm{C}$ to identify clearly the dynamics of the rate of the water loss to the temperature. Short-term heat stresses of $40^{\circ} \mathrm{C}$ for about 24
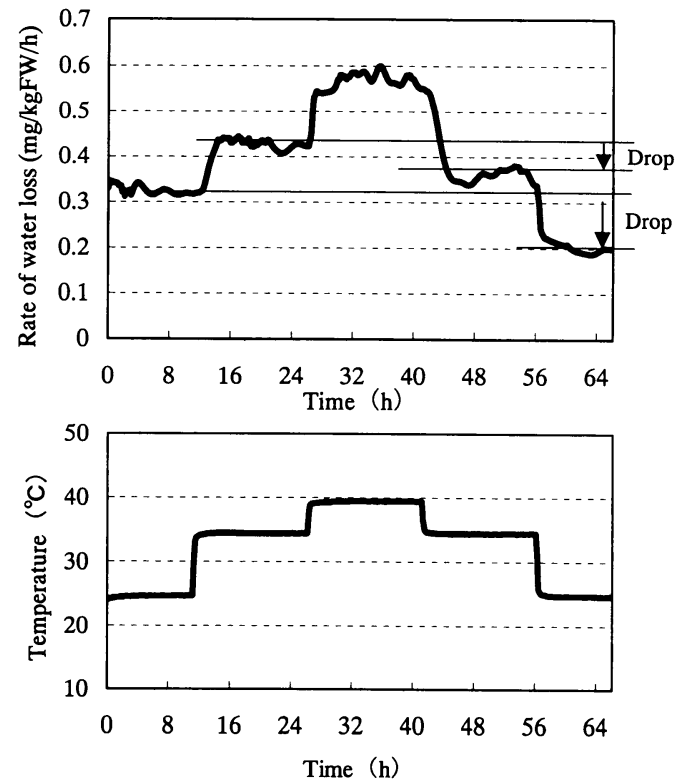

Fig. 10 A typical dynamic change in the rate of the water loss, as affected by the temperature. 
hours were included in several temperature operations. Each data set has a different data number. From the figure, it is found that, in all cases, the rate of the water loss dynamically changes with the temperature.

\section{Identification of the rate of the water loss to temperature}

Next, the data in Fig. 11 are identified using the neural network in order to make a dynamic model for simulation. The system parameter number and the hidden neuron number of the neural network were respectively determined to be $n_{2}=15$ and $\mathrm{n}_{\mathrm{h} 2}=20$ through crossvalidation. These values minimized the error between the estimated and observed values. Figure 12 shows the comparison of the estimated response, calculated from the neural network model, and the observed response for the rate of the water loss. A testing data set, which is quite different from the training data sets shown in Fig. 11, was used for this comparison. It was found that the estimated response was closely related to the observed response. This means that we succeeded in finding a suitable model (simulator) for searching for an optimal value.

Figure 13 shows the estimated relationship between the temperature and the rate of the water loss of a tomato, calculated from the simulation of the identified neural-network model. Open circles represent real observed data. The rate of the water loss increases with temperature. In the range over $35^{\circ} \mathrm{C}$, it has a tendency to decrease with temperature. This means that the water loss was significantly suppressed by high temperature. It is found that the relationship between temperature and the rate of water loss is non-linear.
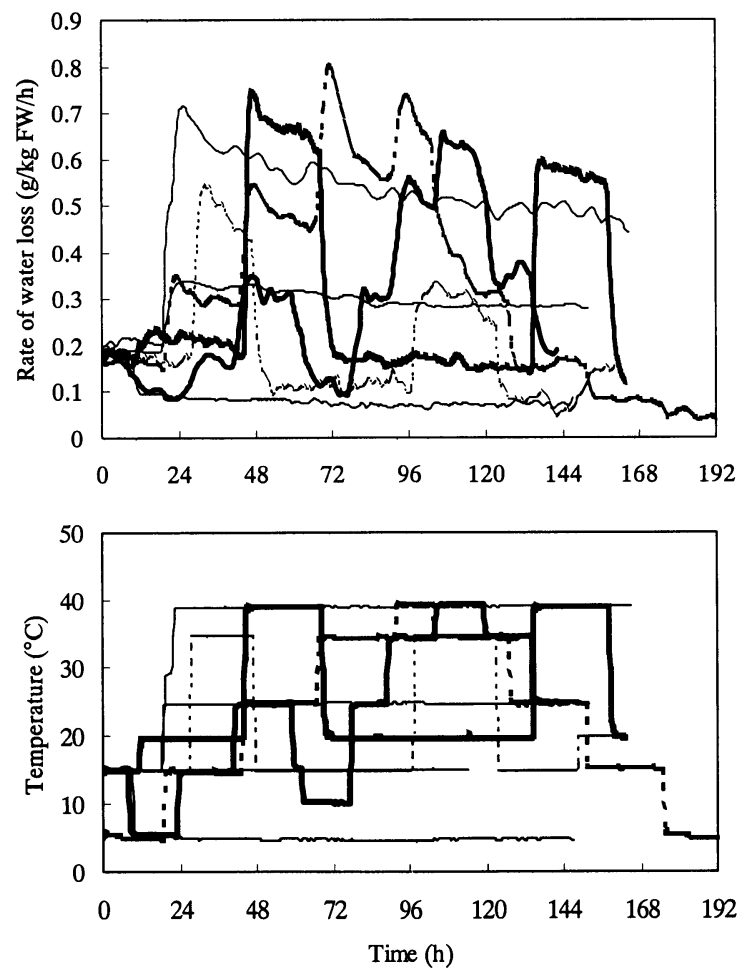

Fig. 11 Eight types of dynamic changes in the rate of the water loss, as affected by temperature. 

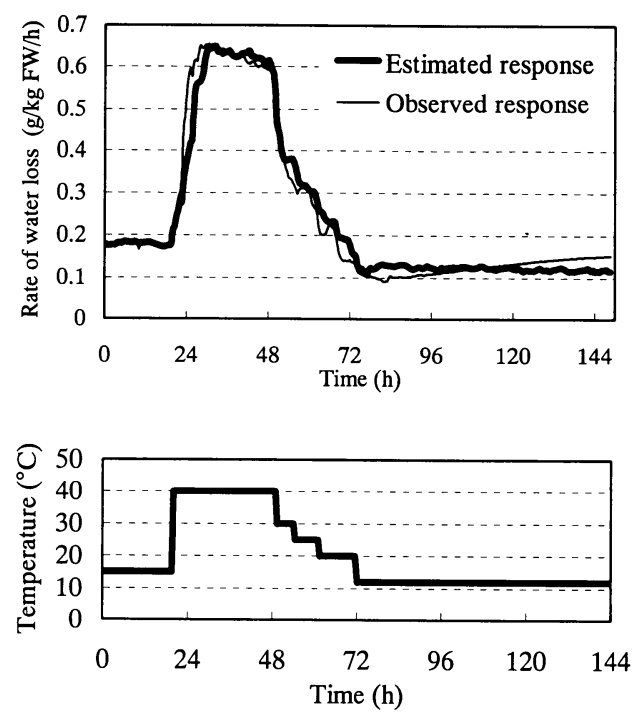

Fig. 12 Comparison of the estimated and observed responses of the rate of the water loss.

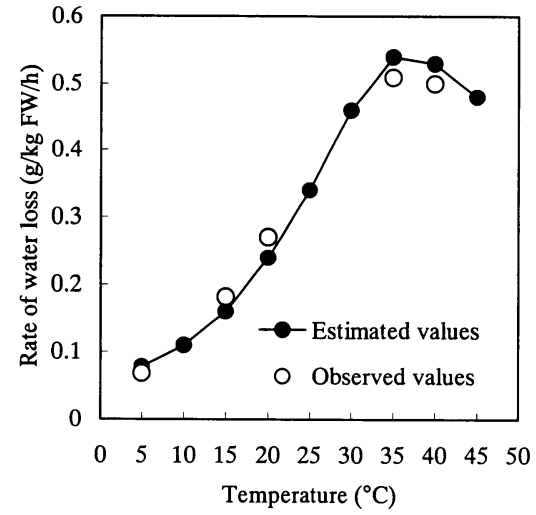

Fig. 13 The static relationship between the temperature and the rate of the water loss, obtained from simulation of the identified model.

\section{Search for an optimal value through model simulation}

Next, the optimal combination of the 6-step set points for temperature that minimized the objective function was searched for through simulation of the identified neural-network model using the genetic algorithm. In this method, the optimal combination was selected from among numerous responses of the rate of the water loss, as affected by any 6-step set point trajectory of the temperature, obtained from simulation.

Figure 14 shows an evolution curve in searching for an optimal value. The crossover rate and the mutation rate were 0.8 and 0.6 , respectively. The searching performance usually depends on the diversity of the population (Morimoto et al., 1995 and 1997b). In this study, therefore, new individuals $(=100)$ in another population were added to the original population in order to maintain the diversity of the population, as shown in Fig. 4. The selection technique was based on an elitist strategy which retains an individual with maximum fitness for next generation in each generation. From the figure, it is found that the fitness dramati-

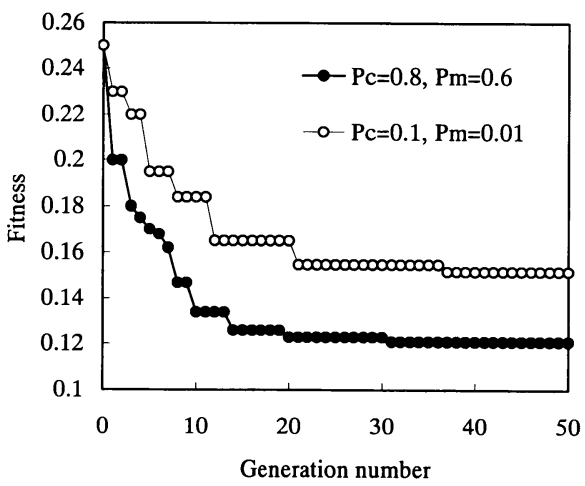

Fig. 14 An evolution curve in searching for an optimal value when the evaluation length is the latter half stage of the control process ( 96 to $168 \mathrm{~h}$ ). 
cally decreased with generation number and then reached the minimum value. The searching procedure is usually stopped when the fitness continues to keep the same minimum value with increasing generation number, and an optimal value can be given by an individual with this minimum fitness. So, it was found that an optimal value was obtained at the 31 st generation number.

Through these investigations, several types of optimal values were obtained under different constraints of the temperature. When the constraint was $5 \leq \mathrm{T}_{l} \leq 40^{\circ} \mathrm{C}$, two optimal values, a combination of only the lowest temperature $\mathrm{T}_{l}=\left\{5,5,5,5,5,5^{\circ} \mathrm{C}\right\}$ and a combination of heat stress and the lowest temperature $\mathrm{T}_{l}=\left\{40,5,5,5,5,5^{\circ} \mathrm{C}\right\}$, were selected. However, there was no significant difference in the rate of the water loss between the two operations. This is because, under a low temperature, these two responses were very small and, consequently, it was difficult to compare their values.

Next, therefore, we increased the minimum temperature level and defined the constraint as $15 \leq \mathrm{T}_{l} \leq 40^{\circ} \mathrm{C}$ in order to extract the effect of the heat stress. In this constraint, we had two optimal values under the different evaluation lengths of the control process. For example, when the evaluation length was the latter half stage of the control process, a single heat stress application of $40^{\circ} \mathrm{C}$ during the first 24 hours, $T_{l}=\left\{40,15,15,15,15,15^{\circ} \mathrm{C}\right\}$, was found to be an optimal value. The length of each step is 24 hours. A double heat stress application, $\mathrm{T}_{l}=\left\{40,15,40,15,15,15^{\circ} \mathrm{C}\right\}$, was also found to be an optimal value when the evaluation length was restricted to the final step (only the last two steps $=2$ days) of the control process. Two optimal values (single and double heat stresses) were characterized by the combination of the highest temperature $\left(40^{\circ} \mathrm{C}\right)$ and the lowest temperature $\left(15^{\circ} \mathrm{C}\right)$.

\section{Optimal control performances in a real system}

Finally, the optimal values (single and double heat stresses) obtained were applied to a real storage system. Figure 15 shows an optimal control performance of the rate of the water loss when an optimal value (a single heat stress) was applied to the fruit. The initial temperature was kept at $15^{\circ} \mathrm{C}$ for 24 hours, and then the optimal control started. The 6-day control process from 24 to 168 hours was divided into 6-step. In this case, the evaluation
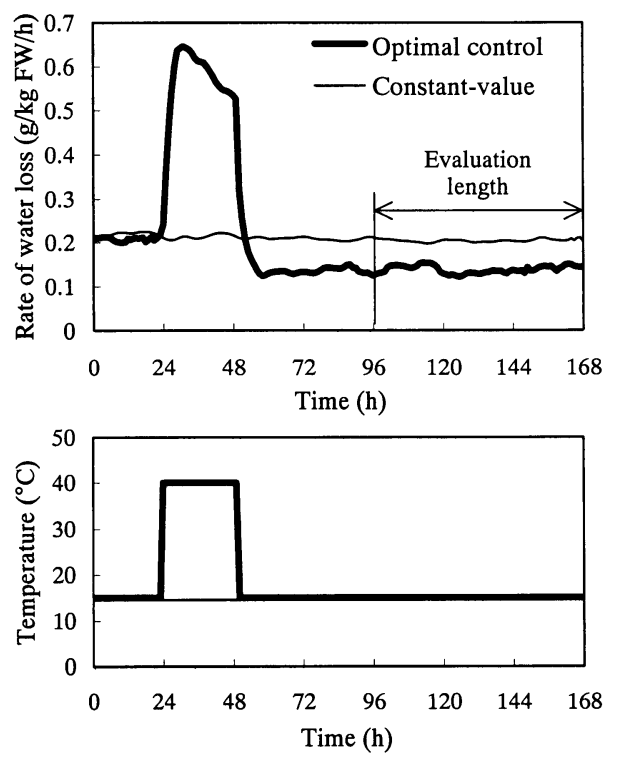

Fig. 15 An optimal control performance of the rate of the water loss when the evaluation length is the latter half stage of the control process $(96$ to $168 \mathrm{~h})$ under the temperature range $\left(15 \leq \mathrm{T}(\mathrm{k}) \leq 40^{\circ} \mathrm{C}\right)$. 

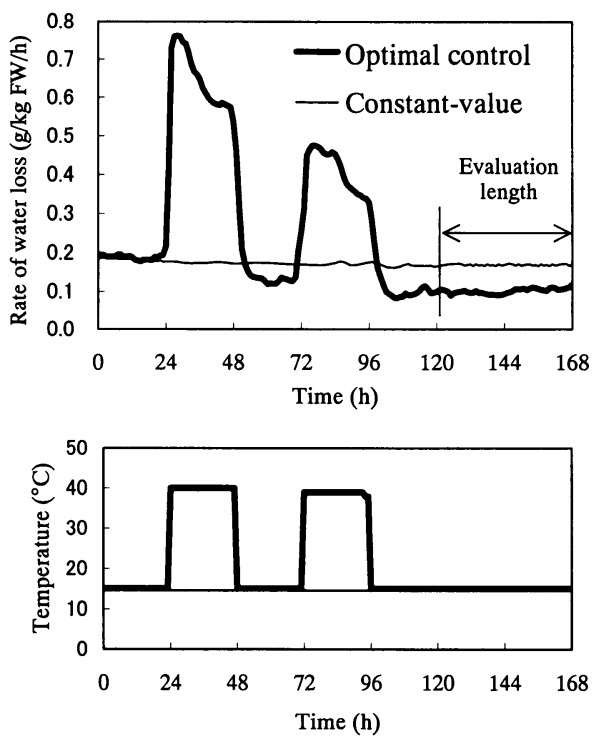

Fig. 16 An optimal control performance of the rate of the water loss when the evaluation length is only the last two stages of the control process $(120$ to $168 \mathrm{~h})$ under the temperature range $\left(15 \leq \mathrm{T}(\mathrm{k}) \leq 40^{\circ} \mathrm{C}\right)$.

length is the latter half step of the control process (96-168 $\mathrm{h}=3$ days), and the constraint of the temperature is $15 \leq \mathrm{T} \leq 40^{\circ} \mathrm{C}$. It is found that, after the single heat stress application, the rate of the water loss becomes lower in the optimal control than in the constant-value control.

Figure 16 shows an optimal control performance of the rate of the water loss when an optimal value (double heat stresses) was applied to the fruit. In this case, the evaluation length was only the last two steps of the control process $(120-168 \mathrm{~h}=2$ days), and the constraint was $15 \leq \mathrm{T} \leq 40^{\circ} \mathrm{C}$. The initial temperature was kept at $15^{\circ} \mathrm{C}$ for 24 hours, and then the optimal control started. From the optimal control performance, the rate of the water loss has a tendency to decrease after applying the heat stress. After the double heat stresses, therefore, the value becomes much lower than that in the constant-value control. It is also found that the values of the rate of the water loss during the second heat stress application are much lower than that during the first heat stress application. This is because the first heat stress significantly suppressed the water loss of the fruit. It was confirmed that this significant reduction after the second heat stress application still continues for at least 3 or 4 more days from other experiments.

The reduction of the water stress caused by the heat stress suggests that the heat-stress fruits acquired a transient thermo-tolerance (Kimpel and Key, 1985; Lurie and Klein, 1991). Especially, controlling temperature so that it first rises to the highest level and then drops to the lowest level seems to be effective at reducing the water loss of the fruit during storage, as compared with $15^{\circ} \mathrm{C}$-constant controls.

These results suggest that a control method changing flexibly and optimally on the basis of fruit responses is a better way to maintain fruit quality during storage than a conventional control manner keeping constant at the lowest temperature.

\section{CONCLUSIONS}

A speaking plant-based intelligent control technique consisting of a decision system based on neural networks and genetic algorithms and a feedback control system was applied to the optimizations of hydroponic tomato cultivation and storage. The decision system allowed 
the optimal set point profile of the nutrient concentration that maximizes the TLL/SD ratio during the seedling stage to be successfully obtained. The values of the TLL/SD ratio were 10-15\% higher with this control technique than with a conventional method. This shows that good seedlings were obtained, with better reproductive growth potential. This control technique was also applied to the optimization of the rate of the water loss of tomatoes during storage by the temperature. The optimal temperature operation that raises a high level during the first day after storage and then suddenly drops to the lowest level provided the lower water loss than when the temperature was maintained constantly at the lowest level. These results suggest that a control method changing flexibly and optimally on the basis of plant (or fruit) responses is a better way to improve the quality of the plant during cultivation (or fruit during storage) than a conventional control manner keeping constant at the adequate level, and the "speaking plant"-based intelligent control technique is suitable for the dynamic optimization of both cultivation and storage processes.

\section{REFERENCES}

Biggs, M. S., William, R., Handa, A. 1988. Biological basis of high-temperature inhibition of ethylene biosynthesis in ripening tomato fruit. Physiol. Plant. 72 : 572-578.

Chalabi, Z. S., Bailey, B. J., Wilkinson, D. J. 1996. A real-time optimal control algorithm for greenhouse heating. Comput. Electron. Agric. $15: 1-13$.

Challa, H., van Straten, G. 1993. Optimal diurnal climate control in greenhouses as related to greenhouse management and crop requirements. In "The Computerized Greenhouse" (ed. by Hashimoto, Y., Bot, Day, Tantau, H.-J.), Academic Press, San Diego, p 119-137.

Chen, H. H., Shen, Z. Y., Li, P. H. 1982. Adaptability of crop plants to high temperature stress. Crop Sci. 22 : July-August, 719-725.

Chen, S., Billings, S. A., Grant, P. M. 1990. Non-linear system identification using neural network. Int. J. Control 51(6) : 1191-1214.

De Baerdemaeker, J., Hashimoto, Y. 1994. Speaking fruit approach to the intelligent control of the storage system. Proc. of 12th CIGR World Congress, Milano, Vol. 1 : p 190-197.

Ehret, D. L., Ho, L. C. 1986. Effects of osmotic potential in nutrient solution on diurnal growth of tomato fruit. J. Exp. Bot. 37(182): 1294-1302.

Fukuyama, T., Morimoto, T., Hashimoto, Y. 1986. Environment control of root system of melons cultivated in a computer controlled greenhouse. Environ. Control in Biol. 24: 9-20 (in Japanese with English summary).

Gale, M. Z. J., Ben-Asher, J. 1983. Root aeration in a deep hydroponic system and its effect on growth and yield of tomato. Scientia Hortic. $19: 213-220$.

Goldberg, D. 1989. Genetic algorithms in search, optimization and machine learning, Addison-Wesley, Reading, Massachusetts.

Hashimoto, Y. 1980. Computer control of short-term plant growth by monitoring leaf temperature. Acta Hortic. 106 : 130-146

Hashimoto, Y., Strain, B. R., Ino, T. 1984a. Dynamic behaviour of $\mathrm{CO}_{2}$ uptake as affected by light. Oecologia 63 : 159-165.

Hashimoto, Y., Ino, T., Kramer, P. J., Naylor, A. W., Strain, B. R. 1984b. Dynamic analysis of water stress of sunflower leaves by means of a thermal image processing system. Plant Physiol. 756 : 266269.

Hashimoto, Y. 1989. Recent strategies of optimal growth regulation by the speaking plant concept. Acta Hortic. 260 : 115-121.

Hashimoto, Y. 1997. Applications of artificial neural networks and genetic algorithms to agricultural systems. Comput. Electron. Agric. 18: 71-72.

Hofman, P. J., Tubbings, B. A., Adkins, M. F., Meiburg, G. F., Woolf, A. B. 2000. Hot water treatments improves 'Hass' avocado fruit quality after cold disinfestation. Postharvest Biol. Technol. 24: 183192. 
Holland, J. H. 1992. Genetic algorithms. Scientific American, July, 44-50.

Hurd, R. G. 1978. The root and its environment in the nutrient film technique of water culture. Acta Hortic. 82 : 87-97.

Ioslovich, I., Seginer, I. 1998. Approximate seasonal optimization of the greenhouse environment for a multi-state-variable tomato model. Trans. ASAE 41 : 1139-1149.

Isermann, R., Ernst, S., Nelles, O. 1997. Identification with dynamic neural. Preprints of 11 th IFAC Symp. on System Identification, Fukuoka, Japan, Vol. 3, 997-1022.

Kimpel, J. A., Key, J. L. $1985 . \quad$ Heat shock in plants. Trends in Biochem. Sci. 10 : 353-357.

Krishnakumar, K., Goldberg, D. E. 1992. Control system optimization using genetic algorithms. J. Guidance, Cont. Dynamics 15 : 735-740.

Liu, F. W. 1978. Modification of apple quality by high temperature. J. Am. Soc. Hortic. Sci. 103: $730-$ 732.

Luo, H., Kato, T. 1987. Studies on the characteristics of seedlings raised in pot under various conditions and their productivity in eggplant and sweet pepper. Environ. Control in Biol. 25: 91-96 (in Japanese).

Lurie, S., Klein, J. D. 1991. Acquisition of low-temperature tolerance in tomatoes by exposure to high-temperature stress. J. Am. Soc. Hortic. Sci. 116 : 1007-1012.

Marsh, L. S., Albright, L. D. 1991. Economically optimum day temperature for greenhouse hydroponic lettuce production. Trans. ASAE 34 : 557-562.

Mizrahi, Y., Taleisnik, E., Kagan-Zur, V., Zohar, Y., Offenbach, R., Matan, E., Golan, R. 1986. A saline irrigation regime for improving tomato fruit quality without reducing yield. J. Am. Soc. Hortic. Sci. 113 : 202-205.

Morimoto, T., Cho, I., Hashimoto, Y. 1991. Identification of hydroponics in an advanced control system of the greenhouse. Preprints of 9th IFAC Symp. on Identification and System Parameter Estimation, Budapest, Hungary, p 610-615.

Morimoto, T., Torii, T., Hashimoto, Y. 1995. Optimal control of physiological processes of plants in a green plant factory. Control Eng. Practice 3 : 505-511.

Morimoto, T., Hatou, K., Hashimoto, Y. 1996. Intelligent control for plant production system. Control Eng. Practice 4 : 773-784.

Morimoto, T., De Baerdemaeker, J., Hashimoto, Y. 1997a. An intelligent approach for optimal control of fruit-storage process using neural networks and genetic algorithms. Comput. Electron. Agric. 18 : 205-224.

Morimoto, T., Purwanto, W., Suzuki, J., Hashimoto, Y. 1997b. Optimization of heat treatment for fruit during storage using neural networks and genetic algorithms. Comput. Electron. Agric. 19: 87-101.

Morimoto, T., Purwanto, W., Suzuki, J., Hashimoto, Y. 1997c. Identification of cumulative fruit responses during the storage process using neural networks. Preprints of 11 th IFAC Symposium on System Identification, Fukuoka, Japan, Vol. 3, 1555-1560.

Morimoto, T., Hashimoto, Y. 2000. An intelligent control for greenhouse automation, oriented by the concepts of SPA and SFA - An application to post-harvest process-. Comput. Electron. Agric. 29 : $3-20$.

Narendra, K. S., Parthasarathy, K. 1990. Identification and control of dynamical systems using neural networks. IEEE Trans. Syst., Man, Cybern. 1: 4-27.

Paull, R. E., Chen, N. J. 2000. Heat treatment and fruit ripening. Postharvest Biol. Technol. 21 : 21-37.

Rumelhart, D. E., Hinton, G. E., Williams, R. J. 1986 . Learning representation by back-propagation error. Nature 323 : 533-536.

Sabehat, A., Weiss, D., Lurie, S. 1996. The correlation between heat-shock protein accumulation and persistence and chilling tolerance in tomato fruit. Plant Physiol. 110 : 531-537.

Shellie, K. C., Mangan, R. L. 1994. Postharvest quality of 'Valencia' orange after exposure to hot, moist, forced air for fruit fly disinfestation. HortScience 29 : 1524-1527.

Sigrimis, N., Rerras, N. 1996. A linear model for greenhouse control. Trans. ASAE 39: 253-261.

Tantau, H.-J. 1993. Optimal control for plant production in greenhouses. In "The Computerized Greenhouse" (ed. by Hashimoto, Y., Bot, Day, Tantau, H.-J., Nonami, H.), Academic Press, San Diego, p 139-152. 